\title{
Caracterización de lixiviados generados del raquis de plátano (Musaceae paradisiaca I)
}

\section{Characterization of leachates generated from the plane tree rachis (Musaceae paradisiaca I)}

\section{Caracterização de lixiviados gerados a partir da banana rachis (Musaceae paradisiaca I)}

\author{
Andrade Quiñones Yudi Paolin ${ }^{1}$, Hidalgo Nieto Angela María ${ }^{1}$ y \\ Herrera Baquero Carlos Alberto ${ }^{2}$ \\ ${ }^{1}$ Ingenierio Agrónomo, Universidad de los Llanos y \\ 2Ingenierio Agrónomo, MSc, Docente Universidad de los Llanos \\ cherrera@unillanos.edu.co
}

Recibido 03 de Diciembre 2018, Aceptado 27 de Mayo 2019

\section{RESUMEN}

Este trabajo evaluó el contenido microbiológico y fisicoquímico del lixiviado producto del compostaje de raquis del plátano, proveniente de fincas de tres municipios del Meta, Colombia: Granada, Fuente de Oro y Villavicencio. La caracterización de hongos y bacterias fue realizada mediante examen microscópico, en el que se observaron algunas de sus estructuras, adicionalmente se tomaron fotografías y posteriormente comparando con lo reportado en la literatura, se definió el género del microorganismo, teniendo en cuenta el aspecto de la colonia. Para la caracterización fisicoquímica se realizó análisis de tipo multivariado mediante correlaciones de Pearson, mientras que la biodegradabilidad de los lixiviados se evaluó mediante la prueba de Tukey con una confiabilidad del 95\%. Se identificó un orden bacterias Actinomicetos con cuatro géneros Clavibacter, Erwinia, Pseudomonas, Agrobacterium y cinco géneros de hongos Fusarium, Aspergillium, Mucor, Rhizopus y Geomyces, distribuidos en las tres localidades con diferente frecuencia. En la caracterización físicoquímica de los lixiviados, según el test de Tukey no se presentaron diferencias ( $\mathrm{P}>0.05$ ); el pH y los sólidos totales (ST) de los lixiviados, es decir la materia suspendida o disuelta sedimentable, variaron entre 8,3 
y $17.666 \mathrm{mg} / \mathrm{L}$ para los materiales de Fuente de Oro, y 8,9 y $18.882 \mathrm{mg} / \mathrm{L}$ para los de Villavicencio, presentando $\mathrm{pH}$ alcalinos en todos los casos; además se presentó una alta alcalinidad de los lixiviados que varió alrededor de $13.529 \mathrm{mgCaCO}_{3} / \mathrm{L}$ para los de Fuente de Oro y $14100 \mathrm{mgCaCO}_{3} / \mathrm{L}$ para los de Granada; por otra parte la turbidez de las muestras varió entre 130 NTU en los materiales de Villavicencio y 231 NTU en los de Fuente de Oro; los contenidos de potasio $(K)$ de los lixiviados fueron altos variando entre 4.620 y $5.300 \mathrm{mg} / \mathrm{L}$ en Villavicencio y Granada respectivamente, indicando que los lixiviados de las tres zonas son poco biodegradables; según las correlaciones de Pearson los lixiviados por sus altos contenidos en potasio requieren de un mayor tiempo de maduración para disminuir la dureza y la alcalinidad, reduciéndose así la presencia de los iones bicarbonato, carbonato, magnesio y calcio en las muestras. Las correlaciones de Pearson indicaron que el $\mathrm{pH}$ de los lixiviados estuvo positivamente correlacionado con los ST $(r=0.99)$, la alcalinidad $(r=0.94)$, el hierro $(F e)(r=0.93)$ y la demanda química de oxígeno (DQO) $(r=1.0)$; el pH guardo una correlación negativa con la turbidez $(r=-$ 0.99) y la dureza total $(r=-0.94)$. Los lixiviados de Fuente de Oro y Granada estuvieron más cercanos en cuanto a los resultados de caracterización fisicoquímica, indicando mayor biodegradabilidad de los mismos (30\%), comparados con los de Villavicencio (20\%).

Palabras clave: Compostaje, biodegradación, microorganismos, análisis fisicoquímico.

\section{ABSTRACT}

This work evaluated the microbiological and physicochemical content of the leachate product of the banana rachis composting, coming from farms in three municipalities of Meta, Colombia: Granada, Fuente de Oro and Villavicencio. The characterization of fungi and bacteria was performed by microscopic examination, in which some of its structures were observed, additionally photographs were taken and later compared with what was reported in the literature, the genus of the microorganism was defined, taking into account the appearance of the colony. For the physicochemical characterization, multivariate analysis was performed using 
Pearson correlations, while the biodegradability of the leachate was evaluated using the Tukey test with a 95\% reliability. An order Actinomycete bacteria was identified with four genera Clavibacter, Erwinia, Pseudomonas, Agrobacterium and five genera of fungi Fusarium, Aspergillium, Mucor, Rhizopus and Geomyces, distributed in the three locations with different frequency. In the physicochemical characterization of the leachate, according to the Tukey test there were no differences $(\mathrm{P}>0.05)$; the $\mathrm{pH}$ and total solids (ST) of the leachate, that is to say the suspended or sedimentable dissolved matter, varied between 8,3 and $17.666 \mathrm{mg} / \mathrm{L}$ for the materials of Fuente de Oro, and 8.9 and $18.882 \mathrm{mg} / \mathrm{L}$ for those of Villavicencio, presenting alkaline $\mathrm{pH}$ in all cases; in addition, there was a high alkalinity of the leachate that varied around $13.529 \mathrm{mg} \mathrm{CaCO}_{3} / \mathrm{L}$ for those of Fuente de Oro and $14100 \mathrm{mg} \mathrm{CaCO}_{3} / \mathrm{L}$ for those of Granada; on the other hand the turbidity of the samples varied between 130 NTU in Villavicencio materials and 231 NTU in those of Fuente de Oro; the potassium $(K)$ contents of the leachate were high varying between 4.620 and $5.300 \mathrm{mg} / \mathrm{L}$ in Villavicencio and Granada respectively, indicating that the leachate from the three zones is not very biodegradable; according to Pearson's correlations, leachates due to their high potassium content require a longer maturation time to reduce hardness and alkalinity, thus reducing the presence of bicarbonate, carbonate, magnesium and calcium ions in the samples. Pearson's correlations indicated that the $\mathrm{pH}$ of leachate was positively correlated with the ST $(r=0.99)$, alkalinity ( $r=0.94)$, iron ( $F e)(r=0.93)$ and chemical oxygen demand (COD) $(r=1.0)$; the $\mathrm{pH}$ was negatively correlated with turbidity $(r=-0.99)$ and total hardness $(r=-0.94)$. The leachates from Fuente de Oro and Granada were closer in terms of physicochemical characterization results, indicating greater biodegradability of them (30\%), compared to those of Villavicencio $(20 \%)$.

Keywords: Composting, biodegradation, microorganisms, physicochemical analysis.

\section{RESUMO}

Este trabalho avaliou o conteúdo microbiológico e físico-químico do produto lixiviado da compostagem de banana rachis, proveniente de fazendas em três municípios de 
Meta, Colômbia: Granada, Fuente de Oro e Villavicencio. A caracterização de fungos e bactérias foi realizada por exame microscópico, no qual foram observadas algumas de suas estruturas, além disso, foram tiradas fotografias e, posteriormente, comparado ao relatado na literatura, foi definido o gênero do microrganismo, levando em consideração a aparência da colônia. Para a caracterização físicoquímica, a análise multivariada foi realizada por meio das correlações de Pearson, enquanto a biodegradabilidade do lixiviado foi avaliada pelo teste de Tukey, com 95\% de confiabilidade. Uma ordem de bactéria Actinomycete foi identificada com quatro gêneros Clavibacter, Erwinia, Pseudomonas, Agrobacterium e cinco gêneros de fungos Fusarium, Aspergillium, Mucor, Rhizopus e Geomyces, distribuídos nos três locais com frequência diferente. Na caracterização físico-química do lixiviado, de acordo com o teste de tukey, não houve diferenças ( $P>0.05)$; o pH e os sólidos totais (ST) do lixiviado, ou seja, a matéria dissolvida em suspensão ou sedimentável, variaram entre 8,3 e $17.666 \mathrm{mg} / \mathrm{L}$ para os materiais da Fonte de Ouro e 8,9 e 18.882 $\mathrm{mg} / \mathrm{L}$ para os de Villavicencio, apresentando $\mathrm{pH}$ alcalino em todos os casos; além disso, houve uma alta alcalinidade do lixiviado que variou em torno de $13.529 \mathrm{mg}$ de $\mathrm{CaCO}_{3} / \mathrm{L}$ para os de Fuente de Oro e $14100 \mathrm{mg}$ de $\mathrm{CaCO}_{3} / \mathrm{L}$ para os de Granada; por outro lado, a turbidez das amostras variou entre 130 NTU em materiais Villavicencio e 231 NTU em Fuente de Oro; o teor de potássio (K) do lixiviado foi alto, variando entre 4.620 e 5.300 mg/L em Villavicencio e Granada, respectivamente, indicando que o lixiviado das três zonas não é muito biodegradável; De acordo com as correlações de Pearson, os lixiviados, devido ao seu alto teor de potássio, requerem um tempo de maturação mais longo para reduzir a dureza e a alcalinidade, reduzindo a presença de íons bicarbonato, carbonato, magnésio e cálcio nas amostras. As correlações de Pearson indicaram que o pH do lixiviado estava positivamente correlacionado com ST $(r=0.99)$, alcalinidade $(r=$ 0.94), ferro ( $F e)(r=0.93)$ e demanda química de oxigênio (DQO). $(r=1.0)$; o pH foi negativamente correlacionado com turbidez $(r=-0.99)$ e dureza total $(r=-0.94)$. Os lixiviados de Fuente de Oro e Granada foram mais próximos em termos de resultados de caracterização físico-química, indicando maior biodegradabilidade deles (30\%), em comparação com os de Villavicencio (20\%). 
Palavras-chave: Compostagem, biodegradação, microorganismos, análise físicoquímica.

\section{INTRODUCCIÓN}

El plátano es uno de los cultivos comerciales más importantes en la economía de diferentes zonas ubicadas en el trópico y hace parte de la dieta alimenticia de la población más pobre de estos países, que, junto con las raíces y los tubérculos, aporta cerca del $40 \%$ del total de la oferta de alimentos en términos de calorías (Castaño et al., 2012). La problemática que ha incentivado diferentes estudios sobre el aprovechamiento de los residuos de cosecha del plátano radica en que el producto principal es el fruto o "dedos" del racimo, en el cual se enfoca especial cuidado para tener una producción de calidad, pero se pierde casi el $70 \%$ de la biomasa de la planta la cual no es aprovechada. Según Álvarez et al., (2013) en las etapas de cosecha y post cosecha, se generan grandes cantidades de residuos foliares, pseudotallo, bellotas, raquis, calidades de segunda y tercera y cáscaras de frutos, que, al carecer de un tratamiento o disposición adecuada, se convierten en contaminantes para el medio ambiente generando la multiplicación de plagas y enfermedades que afectan la producción y calidad de los cultivos.

El aprovechamiento de los residuos de cosecha se ha utilizado en la fabricación de harinas para alimentación de animales, abonos e incluso fungicidas y activadores microbiológico, una de las partes del plátano que mayor potencial nutricional contiene es el raquis, el cual queda como residuo luego del corte del racimo, su contenido nutricional es alto y puede variar con la fertilidad del suelo y disponibilidad de nutrientes (Aristizabal y Jaramillo, 2010). A partir de éste se pueden obtener lixiviados los cuales están compuestos por ácidos húmicos y fúlvicos, que han sido utilizados en control de enfermedades fungosas en cultivos como tomate, rosas y el mismo plátano. En el momento de la cosecha y el proceso de comercialización del plátano solo se usa el fruto lo que equivale a un $20 \%$ o $30 \%$ del total de la biomasa de la planta, el restante $70 \%$ a $80 \%$ en algunos casos es reciclado para abono orgánico o para alimentación animal debido a su alto porcentaje de nutrientes (Reyes et al., 2015). 
Para tener un estimado de qué nutrientes y posibles cantidades que se pueden obtener en los lixiviados de raquis de plátano (tallo floral), es necesario conocer su composición; según Álvarez et al., (2013), este subproducto contiene materia orgánica parcialmente descompuesta, microorganismos benéficos y alto contenido de nutrientes (especialmente potasio) (Tabla 1).

Tabla 1. Análisis químico de lixiviados de raquis de plátano con tiempo de mayor producción a un año

\begin{tabular}{cccc}
\hline Elemento & Contenido $(\mathbf{m g} / \mathbf{L})$ & Elemento & Contenido $(\mathbf{m g} / \mathbf{L})$ \\
\hline Nitrógeno & $205-307.5$ & Boro & $0.12-1.3$ \\
Fósforo & $174-268.9$ & Hierro & $0.5-7.7$ \\
Potasio & $15.6-22.4$ & Manganeso & $0.51-2.8$ \\
Calcio & $28.5-64$ & Zinc & $0.06-0.4$ \\
Magnesio & $18-43.4$ & Cobre & $0.5-0.6$ \\
Azufre & $55.7-342.7$ & Sodio & $27.2-30.1$ \\
\hline
\end{tabular}

Fuente: Álvarez et al., (2013)

El lixiviado se puede definir como el líquido residual generado por la descomposición biológica de la materia orgánica o biodegradable de los desechos bajo condiciones aeróbicas y anaeróbicas o como resultado de la percolación del agua a través de los residuos en proceso de degradación (Meneses et al., 2010).

La estabilización de la materia orgánica, se puede lograr bajo condiciones que permitan un desarrollo de temperaturas hemofílicas como consecuencia de una producción biológica de calor, que da un producto final estable, libre de patógenos y semillas de malas hierbas y que aplicado al terreno produce un beneficio (Benavides, 2010). Los factores más importantes en el proceso biológico de maduración del compostaje son la temperatura, humedad, acidez/alcalinidad $(\mathrm{pH})$, aireación, relación $\mathrm{C}: \mathrm{N}$, capacidad de intercambio catiónico $(\mathrm{CIC})$, población microbiana y presencia de microorganismos patógenos (Losada, 2012).

Se reconocen cuatro etapas dependiendo de la temperatura que se genera durante el proceso de descomposición que son: Fase Mesófila, dura entre dos y ocho días, se aumenta la temperatura hasta los $45^{\circ} \mathrm{C}$ y los microorganismos utilizan las fuentes 
sencillas de $\mathrm{C}$ y $\mathrm{N}$ generando calor, bajando el $\mathrm{pH}$ hasta 4.0. Fase Termófila $\mathrm{o}$ de Higienización, dura días hasta meses, cuando el material alcanza temperaturas de $60^{\circ} \mathrm{C}$ y actúan microorganismos termófilos que degradan fuentes complejas de $\mathrm{C}$, como la celulosa y la lignina; estas altas temperaturas destruyen bacterias y contaminantes de origen fecal como Eschericha coli y Salmonella spp, quistes y huevos de helmintos, esporas de hongos fitopatógenos y semillas de malezas. Fase de Enfriamiento o Mesófila II, esta fase requiere de varias semanas y puede confundirse con la fase de maduración, la temperatura desciende nuevamente hasta los $45^{\circ} \mathrm{C}$. Durante esta fase, continúa la degradación de polímeros como la celulosa, y aparecen algunos hongos visibles a simple vista y el $\mathrm{pH}$ del medio desciende levemente, aunque en general se mantiene ligeramente alcalino. Fase de Maduración, demora meses a temperatura ambiente, durante los cuales se producen reacciones secundarias de condensación y polimerización de compuestos carbonados para la formación de ácidos húmicos y fúlvicos. (Losada, 2012).

En los parámetros fisicoquímicos el rango de $\mathrm{pH}$ y acidez en los lixiviados varía, según la etapa de maduración, entre más jóvenes sean su pH es más ácido y puede descender hasta cuatro, por la presencia de los ácidos orgánicos y por las elevadas concentraciones de $\mathrm{CO}_{2}$, que se dan durante las primeras fases de descomposición, en la maduración del lixiviado el pH empieza a ascender y puede adquirir valores entre 6.8 a 8 , lo cual genera un medio básico propicio para la polimerización. (Mendoza, 2004; Torrez et al., 2018). Los valores de alcalinidad están en un rango de 300-11500 mg de $\mathrm{CaCO}_{3} / \mathrm{L}$, y no varían dependiendo de la fase en la que se encuentre el lixiviado; la alcalinidad se determina por titulación con un ácido normalizado, expresándose los resultados en carbonato de calcio $\mathrm{CaCO}_{3}$ (Tabla 2).

La demanda química de oxígeno (DQO) se define como la cantidad de un oxidante específico que reacciona con una muestra bajo condiciones controladas para oxidar la materia orgánica en una muestra de agua, bajo condiciones específicas de agente oxidante, temperatura y tiempo, la cantidad oxidada es expresada en términos de su equivalencia en oxígeno: $\mathrm{mg}$ de $\mathrm{O}_{2} / \mathrm{L}$ (Benavides, 2011). 
Un parámetro generalmente utilizado para identificar la biodegradabilidad de los diversos tipos de vertidos, es la relación entre las demandas bilógica y química del oxígeno (DBO5/DQO), la cual permite determinar qué cantidad de la DQO (materia orgánica e inorgánica contenida en una muestra) de un vertido es susceptible de ser depurada por los microorganismos en cinco días (DBO5) (Tabla 3).

Tabla 2. Características fisicoquímicas de un Lixiviado

\begin{tabular}{cccc}
\hline Edad del relleno & Menor de 2 años & Menor de 2 años & 10 años \\
\cline { 2 - 4 } Constituyentes & Rango & Valor típico & Rango típico \\
\hline DQO & $3000-60000$ & 18000 & $100-500$ \\
DBO5 & $2000-30000$ & 10000 & $100-200$ \\
COT & $1500-20000$ & 6000 & $80-160$ \\
SST & $200-2500$ & 500 & $100-400$ \\
Nitrógeno Total & $20-1500$ & 400 & $100-200$ \\
Fósforo Total & $5-100$ & 30 & $5-10$ \\
Alcalinidad (CaCO 3$)$ & $1000-10000$ & 3000 & $200-1000$ \\
Sales Solubles & $200-4000$ & 800 & $100-500$ \\
Hierro & $50-1200$ & 60 & $20-200$ \\
Plomo & $1-10$ & 2 & $0.01-0.5$ \\
Zinc & $25-250$ & 50 & $0.1-1$ \\
pH & $5.0-8.0$ & 6 & $6.6-7.5$ \\
\hline
\end{tabular}

DQO = Demanda química de oxígeno; DBO5 = Demanda biológica de oxígeno; COT = Carbono orgánico total; SST = Solidos suspendidos totales.

Fuente: Adaptado de Torrez et al., 2018

Tabla 3. Criterios de biodegradabilidad de diferentes vertimientos según la relación $\mathrm{DBO}_{5} / \mathrm{DQO}$

\begin{tabular}{cc}
\hline $\mathrm{DBO}_{5} / \mathrm{DQO}$ & Carácter \\
\hline 0.8 & Muy biodegradable \\
$0.7-0.8$ & Biodegradable \\
$0.3-0.7$ & Poco biodegradable \\
$<0.3$ & No Biodegradable \\
\hline
\end{tabular}

Se toma como parámetro que la relación $\mathrm{DBO} / \mathrm{DQO}=0.78$, obtenida para el agua residual Fuente: Benavides, (2011). 
El presente trabajo de investigación consistió en realizar la caracterización microbiológica y fisicoquímica de los lixiviados generados a partir del compostaje de raquis de plátano en tres zonas productoras del Meta, Colombia, con el fin de que se avance en la aplicación de estos lixiviados en el control de enfermedades y fertilización de los cultivos, de esta forma se pretende contribuir al desarrollo de cultivos auto sostenibles y limpios que minimicen al máximo el impacto en el medio ambiente.

\section{METODOLOGÍA}

La elaboración de los lixiviados generados a partir de raquis de plátano fue realizado en la Biofábrica de la Universidad de los Llanos, con coordenadas geográficas Norte de 4을 y longitud Oeste de $63^{\circ} 38^{\prime}$, altura $387 \mathrm{msnm}$, precipitación anual promedio $3.479 \mathrm{~mm}$, humedad relativa $82 \%$, temperatura media anual $25.2^{\circ} \mathrm{C}$, máxima $32.5^{\circ} \mathrm{C}$ y mínima $18.5^{\circ} \mathrm{C}$.

La producción de los lixiviados fue realizada por el método de canecas en fermentación aeróbica, técnica que permitió recolectar el lixiviado a través de una llave de paso instalada en la base de la caneca (Figura 1B), cada semana se realizó la recolección de muestras para ser analizadas en los laboratorios de microbiología, fitopatología y suelos. Se utilizaron tres canecas, en donde se recolecto el material vegetal de cada zona, en recipientes separados. Se utilizaron $100 \mathrm{~kg}$ de raquis de plátano (Figura 1A) por caneca los cuales fueron picados previamente, el lixiviado obtenido de cada caneca fue en promedio dos litros, aclarando que no se utilizó agua ni agentes descomponedores inducidos. El tiempo de curado o estabilización fue 6 meses, es decir que se consideraron lixiviados jóvenes, por lo cual se esperaban $\mathrm{pH}$ bajos, porque a esta edad, son bajos en ácidos orgánicos, en comparación con un lixiviado maduro con una fase de producción mayor a un año.

El diseño experimental estuvo constituido por tres tratamientos correspondiendo a cada municipio de donde se trajo el raquis $\mathrm{T} 1=$ lixiviados de Fuente de Oro, T2 = lixiviados de Granada, T3 = lixiviados de Villavicencio, se trabajaron seis repeticiones y de estas se sacó una media. 


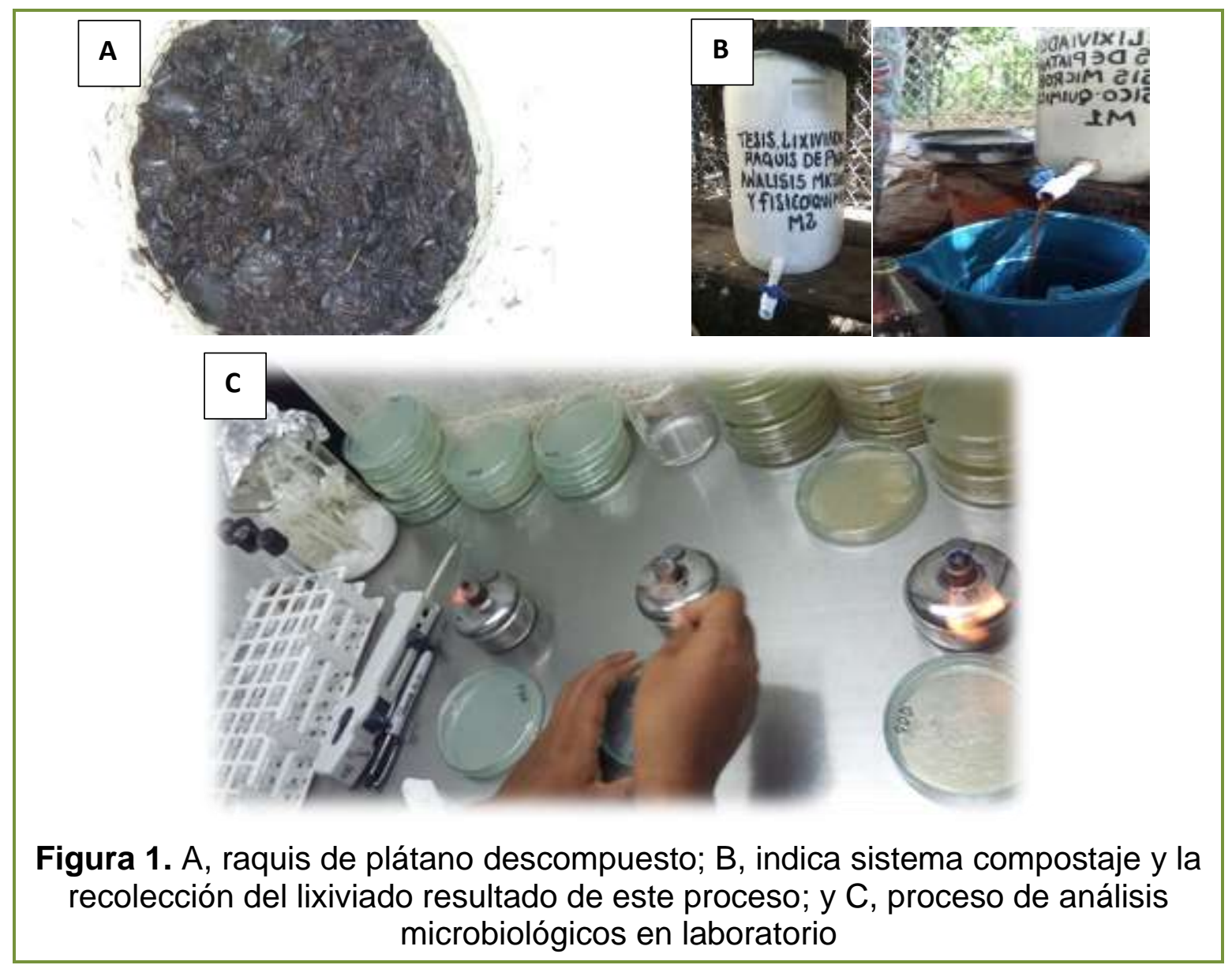

Para realizar la caracterización fisicoquímica de los lixiviados y estudiar su biodegradabilidad se aplicó un análisis multivariado realizando correlaciones de Pearson, aplicando la prueba de Tukey (95\%); se realizó análisis de componentes principales y conformación de clúster según distancias euclidianas, mediante el paquete estadístico INFOSTAT.

El análisis microbiológico consistió en la identificación de los hongos y bacterias en las seis réplicas de cada uno de los tres tratamientos (localidades) al igual que el análisis de tipo fisicoquímico. En la caracterización microbiológica se realizaron siembras en cajas de Petri en Agar Papa Dextrosa (PDA) y Agar Nutriente para hongos y bacterias respectivamente, igualmente seis réplicas por cada tratamiento (Figura 1C). 
La identificación de bacterias se realizó mediante examen microscópico de las colonias, teniendo en cuenta la morfología de la colonia, la caracterización microbiológica se realizó en base a los aspectos cualitativos como color de colonia, forma, aspecto, tinción de Gram, forma de estructuras, movimiento, $\mathrm{KOH}_{6}$ - (para determinar tinción Gram) y $\mathrm{H}_{2} \mathrm{O}_{2}$ (determinación de la capacidad anaerobia 0 aeróbica) siguiendo la metodología propuesta por (Silva et al.,1999; Atlas y Bartha, 2005).

Se tomaron $10 \mathrm{ml}$ de la muestra y se mezclaron en un Erlemeyer con $90 \mathrm{ml}$ de agua oxigenada, esta primera mezcla fue la dilución 100. la cual se agitó durante 5 minutos; posteriormente con una micropipeta se retiró $1 \mathrm{ml}$ de la mezcla y se depositó en un tubo de ensayo que contenía $9 \mathrm{ml}$ de agua oxigenada para obtener así la dilución $10^{-1}$ la cual se agitó por $1 \mathrm{~min}$, luego se pipeteó de este tubo $1 \mathrm{ml}$ que fue diluido en un segundo tubo de ensayo que contenía $9 \mathrm{ml}$ de agua oxigenada para conformar así la dilución $10^{-2}$, repitiendo el procedimiento anterior hasta llegar a $10^{-4}$. Para realizar cada dilución se utilizó una nueva pipeta, esto con el fin de no contaminar las diluciones con las concentraciones anteriores. Del tubo que contenía la dilución $10^{-4}$ se retiró $1 \mathrm{ml}$ y se sembró en el medio Agar Nutriente en cajas Petri, para desarrollo de bacterias con seis repeticiones para cada tratamiento y una muestra concentrada de lixiviado.

La identificación de bacterias se realizó teniendo en cuenta las características usadas para la diferenciación de géneros reconocidos de bacterias fitopatógenas de acuerdo con la Universidad Nacional de Córdoba (UNC, 2015). También se tuvo en cuenta la metodología de Urbina, (2011) la cual describe que la mayoría de las bacterias fitopatógenas poseen delicados flagelos en forma de filamentos que a menudo son considerablemente más largos que las células que los formaron. Algunas especies bacterianas presentan un solo flagelo, mientras que otras poseen un ramillete de flagelos en uno de sus extremos, algunas tienen un flagelo simple o un ramillete de ellos en cada extremo y otras poseen flagelos periticos, es decir, distribuidos sobre toda su superficie. En las especies filamentosas de Streptomyces, 
las células constan de filamentos ramificados cenocíticos (no septados), los cuales a menudo tienen forma espiral y producen conidios en cadena sobre hifas aéreas.

Las colonias de las distintas especies de bacterias varían en tamaño, forma, forma de los bordes, elevación y color u otras características, y en ocasiones dichas variaciones son características de una determinada especie. El diámetro de dichas colonias puede ser desde una fracción de milímetro hasta varios centímetros y pueden ser circulares, ovoides o irregulares. Sus bordes pueden ser lisos, ondulados o angulares y su elevación puede ser plana, saliente, en forma de domo o rugosa. Las colonias de la mayoría de las especies son de color blancuzco o grisáceo, aunque algunas son amarillas, rojas o de otros colores. Algunas producen pigmentos que se difunden en el agar (Silva et al., 1999; Urbina, 2011).

Para los hongos, se repitió el procedimiento anterior, realizando las siembras en PDA, la identificación y clasificación se realizó evaluando aspectos cualitativos relacionados con el micelio (algodonoso, aterciopelado, denso, polvoroso), forma de colonia, coloración, y por comparación literaria sugerida en Silva et al., (1999). La caracterización de hongos se realizó teniendo en cuenta el aspecto de la colonia, y mediante el método de la cinta scotch el cual consiste en levantar al hongo, se colocó en el portaobjetos y se observó en el microscopio óptico para observar algunas de sus estructuras, adicionalmente se tomaron fotografías y luego por comparación literaria se definió el género de hongo. Para esta caracterización se prestó especial atención a los hongos fitopatógenos, entre los cuales se encuentran Colletotrichum, Botrytis, Penicillium, Fusarium, Phytophthora, Rhizoctonia, Phyitium, Phymatotrichum (Agrios, 2005) los cuales están relacionados con los principales hongos del plátano: Fusarium oxysporum Schlecht f. sp. Cúbense y Mycosphaerella fijiensis var. Difformis Morelet.

Para el análisis fisicoquímico se tomó una muestra madre, de la cual se obtuvo un litro de cada tratamiento, este análisis se realizó en el laboratorio de Aguas y Suelos de la Universidad de Los Llanos, los parámetros evaluados se detallan en la en la Tabla 4. 
Tabla 4. Parámetros fisicoquímicos evaluados

\begin{tabular}{ccc}
\hline Parámetro fisicoquímico & Método analítico & Unidades \\
\hline $\mathrm{pH}$ & Potenciómetro & \\
Solidos totales & Método gravimétrico & $\mathrm{mg} / \mathrm{l}$ \\
Acidez & Método titulación & $\mathrm{mgCaCO}_{3} / \mathrm{l}$ \\
Alcalinidad & Método titulación & $\mathrm{mgCaCO} / /$ \\
Turbidez & Espectro fotométrico & $\mathrm{NTU}$ \\
Potasio & Absorción atómica & $\mathrm{mg} / \mathrm{l}$ \\
Sodio & Absorción atómica & $\mathrm{mg} / \mathrm{l}$ \\
Dureza cálcica & Método titulación & $\mathrm{mg} / \mathrm{l}$ \\
Dureza total & Método titulación & $\mathrm{mg} / \mathrm{l}$ \\
Hierro & Absorción atómica & $\mathrm{mg} / \mathrm{l}$ \\
Cloruros & Método titulación & $\mathrm{mg} / \mathrm{l}$ \\
\hline
\end{tabular}

RESULTADOS Y DISCUSIÓN

\section{Caracterización de bacterias}

En los lixiviados de las tres localidades fue encontrado un mayor número de actinomicetos con respecto a los otros géneros, reportándose una mayor abundancia de este orden en Granada (6), seguidamente en Villavicencio (5) y en Fuente de Oro (4). Con respecto a los géneros, Clavibacter fue más común en Fuente de Oro (3) y no se encontraron en las otras dos localidades, por su parte, Erwinia solo se reportó en los lixiviados del plátano de Granada, pero Pseudomonas y Agrobacterium fueron comunes en los lixiviados de Villavicencio, con una abundancia de (1) cada uno respectivamente (Grafica 1).

El análisis microbiológico permitió caracterizar cinco grupos de bacterias: Actinomicetos, clavibacter, Erwinia, Pseudomonas, Agrobacterium, las cuales en general presentan características y referencias como bacterias fitopatógenas y descomponedores de residuos orgánicos, en especial al filo de actinomicetos son 
controladores de hongos e incluso de nematodos que pueden ser un riesgo fitosanitario para los cultivos, si se presentase especialmente el género Streptomyces, hongo de morfología filamentosa y septada, podría ser un riesgo para los cultivos, pero no fue identificado en las improntas tomadas de los medios de cultivo, sin embargo esto no descarta una posible presencia del mismo, en los lixiviados.

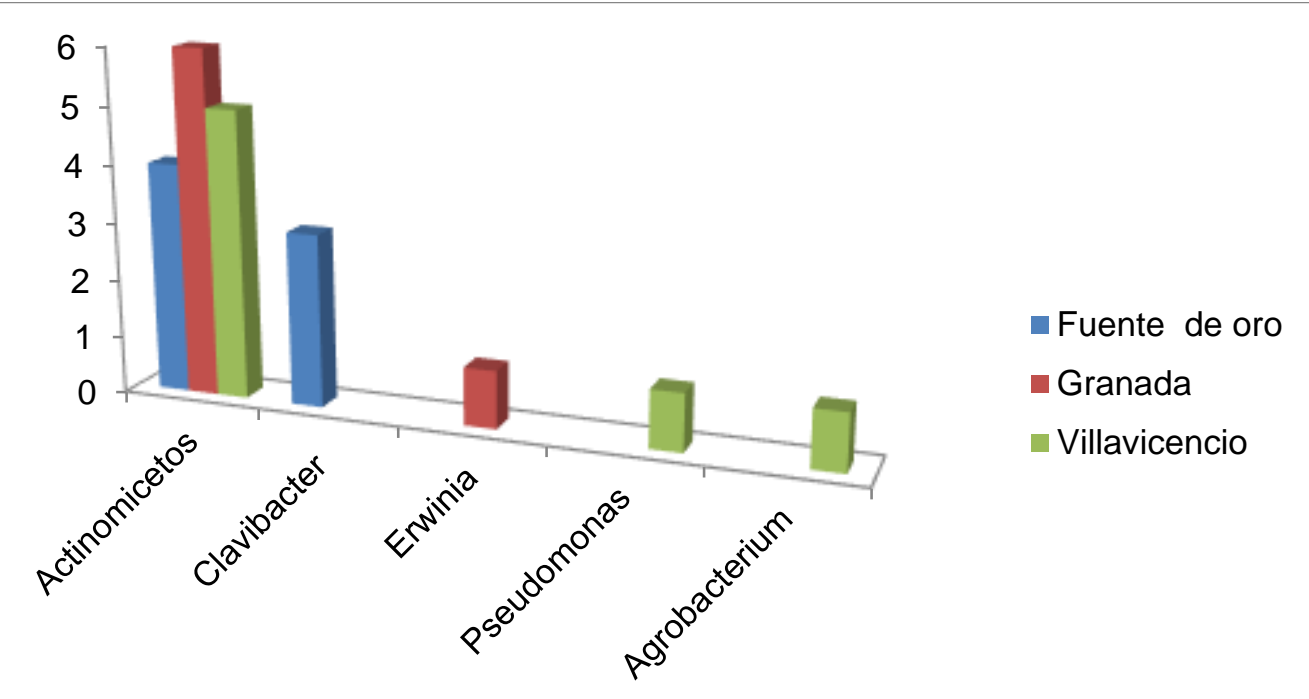

Gráfica 1. Frecuencia de bacterias en los lixiviados del raquis

En la aproximación a grupo y género de acuerdo con la morfología y pruebas realizadas, se encontraron características propias del grupo de los actinomicetos en donde se encuentran bacterias patógenas y descomponedores las cuales crecen sobre material en descomposición, por lo que transforman una gran variedad de residuos orgánicos complejos, y forman parte importante de la población de lagos, ríos y suelos (Parada et al., 2017), adicionalmente se les confiere algunas propiedades como controladores biológicos.

En su gran mayoría dentro de las propiedades de los actinomicetos se tiene la capacidad de producir metabolitos nematocidas, controlando uno de los patógenos más importantes: Meloidogyne spp, organismo que ha generado grandes pérdidas económicas en Colombia, debido a que afecta el rendimiento de cultivos de hortalizas, plantas medicinales, oleaginosas, frutales, té y tabaco; el control de este 
patógeno está limitado a la aplicación de nematocidas, que además de ser costosos son perjudiciales para el medio ambiente y la salud humana. En Colombia no existen muchos reportes acerca de los beneficios en cuanto al control de nematodos por parte de los actinomicetos y la abundancia de estos microorganismos (González, 2010).

Pseudomonas es una bacteria gram negativa en forma de bastón y colonias generalmente blancas o beige catalasa y oxidasa positiva, dentro del género la especie $P$. solanacearum ocasiona grandes pérdidas en banano; el síntoma típico es la marchitez seguida de la muerte. Esto significa que, si la infección ocurre en la fase inicial del ciclo del cultivo y las condiciones son favorables, puede ocasionar su pérdida total. Durante la noche o en las horas más frías del día los foliolos pueden recuperar su turbidez siendo una enfermedad de difícil control. Las plantas con marchitez presentan una progresiva decoloración vascular, más intensa en la base de la planta, que puede ser fácilmente visualizada, además se reporta que las Pseudomonas se encuentran ampliamente en la tierra y el agua, y contribuyen a degradar sustancias químicas en el suelo, como por ejemplo los pesticidas, (Obregón et al., 2008).

Agrobacterium es otro posible género de bacterias presente en el lixiviado de raquis, estas bacterias tienen forma de bastón y sus dimensiones son de $0.8 \times 1.5$ a $3 \mu \mathrm{m}$. Se desplazan por medio de 1 a 4 flagelos perítricos; cuando presentan un solo flagelo, éste con frecuencia es más lateral que polar. Cuando crecen en medios que contienen carbohidratos, estas bacterias producen un abundante mucilaginoso polisacárido. Las colonias no presentan pigmentación y usualmente son lisas. Estas bacterias son habitantes del suelo y de la rizósfera (Urbina, 2011).

Ventura, (2007) reportó los géneros más importantes que causan enfermedades en los cultivos entre los cuales se encuentran Agrobacterium sp, Corynebacterium sp, Erwinia sp, Pseudomonas sp, Xanthomonas sp, al igual que Urbina, (2011) quien adicionalmente describe que la mayoría de las bacterias fítopatógenas tienen forma de bastón; la única excepción es Streptomyces, que es filamentosa y pertenece al filo actinomicetos Entre las bacterias con formas de bacilos se encuentran 
Agrobacterium, Erwinia, Pseudomonas y Xanthomonas que además son bacterias Gram negativas; y en las bacterias Gram positivas se encuentran los géneros Clavibacter, Curtobacterium y Streptomyces (Agrios, 2005).

Clavibacter y Streptomyces pertenecen al grupo de bacterias descomponedores denominada actinomicetos, lo cual para efectos de la caracterización de lixiviados realizada pudo jugar un doble papel, pues estas bacterias son de vital importancia en el proceso de descomposición del material vegetal (raquis), y también al permanecer en las fuentes de agua, en este caso el lixiviado generado de la descomposición del raquis de plátano, se puede convertir en una fuente de diseminación de enfermedades para los cultivos, siempre y cuando no sea realizado un adecuado proceso de maduración (estabilización) del lixiviado.

La mayor abundancia de actinomicetos encontrados en los lixiviados de las tres localidades, tienen una connotación importante, además de controlar nematodos, los actinomicetos también controlan otro tipo de patógenos como Fusarium oxysporum, Colletotrichum gloeosporioides, Colletotrichum musae, Cladosporium fulvum, Stenocarpella maydis, Phytophthora, Rhizoctonia sp y Curvularia eragrostidis entre otros, reportados en la literatura en la producción de metabolitos secundarios y primarios como antibióticos y enzimas extracelulares (González, 2010).

Los actinomicetos a mayor $\mathrm{pH}$ aceleran su actividad en los procesos de descomposición, el pH de los lixiviados de las tres zonas de estudio alrededor de 8 hasta la edad de 6 meses. Los lixiviados contienen materia orgánica parcialmente descompuesta, microorganismos benéficos y alto contenido de nutrientes, en este caso, altos contenidos de potasio especialmente.

Erwinia es una bacteria Gram negativa en forma de bastón y con flagelos perítricos. El género contiene algunas especies saprofitas y varias fitopatógenas. Es la única fitobacteria anaeróbica facultativa, lo que significa que se pueden multiplicar tanto en la presencia como en ausencia de oxígeno. Es oxidasa negativa, catalasa positiva y fermentadora. La coloración de la mayoría de las colonias es crema y 
algunas especies producen colonias amarillas (Ventura, 2007), el hecho de que algunas características correspondan a la descripción de Erwinia, no confirma con certeza que sea este su género, pues habría que realizar pruebas más específicas en las cuales incluso se pudiera avanzar en su identificación para determinar si puede ser un caso de la enfermedad necrosis del cormo, causada por Erwinia chrysanthemi, que afecta de forma considerable el desarrollo del cultivo de plátano (Musa spp) (Jiménez, 1999).

\section{Caracterización de hongos}

La mayor abundancia de Fusarium fue observada en las muestras de Fuente de Oro (3) y seguidamente en Granada (2), disminuyendo su presencia en Villavicencio (1). Aspergillium fue más común en Villavicencio (2), y menos en los lixiviados de Fuente de Oro (1), y no apareció en los lixiviados de Granada. Por otra parte, Mucor presentó abundancia en lixiviados de Fuente de Oro (1), pero no se observó en las otras dos localidades. Rhizopus fue común en las tres localidades, presentándose una abundancia de (1), (2) y (2) en las muestras de Fuente de Oro, Granada y Villavicencio, respectivamente. Geomyces no se encontró en los lixiviados de Fuente de Oro, pero si en Granada (2) y en Villavicencio (1) (Grafica 2).

Los cinco géneros de hongos identificados: Fusarium, Aspergillium, Mucor, Rhizopus, y Geomyces (Gráfica 2), hacen parte de los microorganismos que generan mayores daños de importancia económica para los cultivos. El género Fusarium es un grupo de hongos filamentosos ampliamente distribuidos en el suelo y plantas; debido a su capacidad de crecer a $37^{\circ} \mathrm{C}$, se considera al género Fusarium como el más complejo de los que atacan las raíces de las plantas cultivadas, y uno de los más difíciles de clasificar. Las especies de Fusarium son saprofitas en algunas de sus fases de crecimiento, y pueden o no desarrollar una fase de reproducción sexual según la especie (Figueroa et al., 2010). El género Geomyces se produce en los suelos, los miembros de este género producen esporas pequeñas, unicelulares, ovales o con forma de pera (artroconidias) de hifas existente en racimos ramificados, con forma de árbol. Se dispersa principalmente por el aire y el agua. 


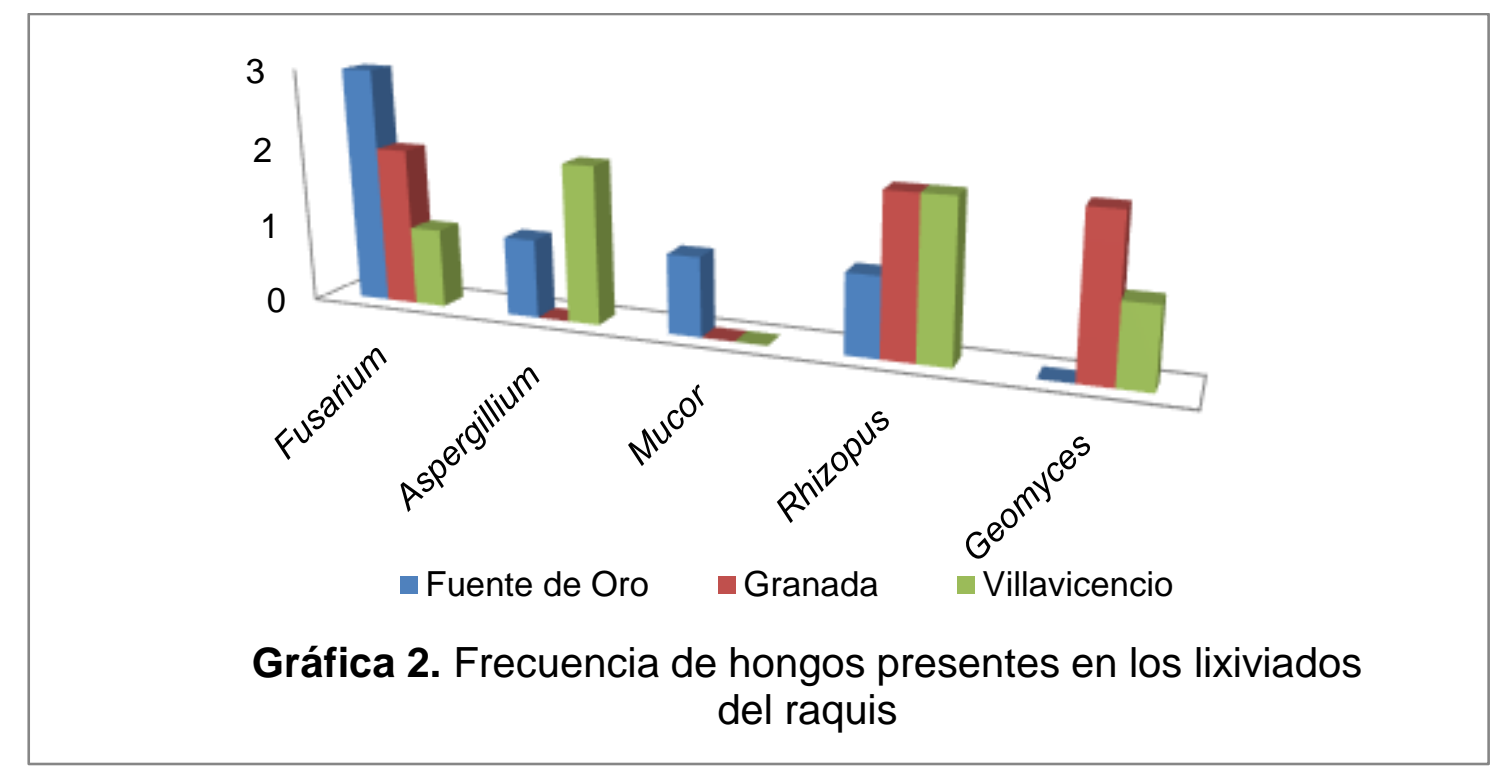

Por otra parte, Aspergillus es un género que pertenece al filum Ascomycota, se caracteriza por producir conidióforos y conidias hialinas. Este hongo se encontró en los dos tipos de muestra analizados, tanto en lixiviados frescos como lixiviados almacenados, un microorganismo ubicuo que normalmente se encuentra en la tierra, el agua y la vegetación podrida y es altamente aeróbico. Los mohos del género Aspergillus causan el deterioro de muchos productos alimenticios son contaminantes comunes de los alimentos con almidón (como pan y papas). Los productos metabólicos de la invasión fúngica suelen ser muy tóxicos, tanto para el hombre como para otros animales (Benavides, 2011). Este hongo tiene gran importancia en el suelo ya que moviliza el fósforo y el nitrógeno del mismo, oxida los sustratos nitrogenados a nitritos, haciendo disponible el nitrógeno para las plantas, degradando ácidos nucleídos y glicerofosfatos a fosfatados simples. Además, es capaz de utilizar una enorme variedad de sustancias como alimento, dada la gran cantidad de enzimas que produce.

Mucor es un hongo con esporas que no son muy abundantes en el aire libre, pero lo son más en lugares donde se acumula vegetación en descomposición y hay un alto grado de humedad, así como en el aserrín y la leña. También se ha aislado de alfombras y del polvo doméstico (Cruz et al., 2017). 
Rhizopus stolonifer es un hongo fitopatógeno versátil que puede crecer en una amplia gama de temperaturas y humedades, lo que le permite colonizar la superficie de los productos agrícolas y causar la enfermedad conocida como pudrición blanda que ocasiona pérdidas económicas. Este proceso se desarrolla mediante la excreción de enzimas que el hongo utiliza para degradar y disolver pectinas de la lámina media de las células vegetales (Velásquez et al., 2008). Se encuentra ampliamente distribuido en la naturaleza sobreviviendo de manera saprófita en el suelo y en residuos orgánicos con el potencial de invadir tejidos vegetales. Entre sus características particulares, se encuentran la formación de micelio aéreo carente de septos y la producción de esporangióforos que presentan en sus puntas en forma esférica donde se alojan las mismas, las cuales muestran diferentes formas: globosas, elipsoidales y angulares con superficies lisas o estrías distintivas (Hernández et al., 2006).

Las esporas de $R$. stolonifer pueden sobrevivir largos períodos sin agua y soportar temperaturas elevadas, germinando sobre tejidos vegetales dañados y generando rápidamente la maceración de los tejidos y la pudrición de los frutos (Velásquez et al., 2008). Estas características son una ventaja para los procesos de descomposición del raquis de plátano que presenta una alta lignificación, y las esporas de este hongo pueden ser eliminados en el proceso de compostaje cuando éste alcanza altas temperaturas las cuales pueden llegar hasta los $50{ }^{\circ} \mathrm{C}$ y el lixiviado puede ser almacenado hasta por un año, estos procesos permiten que las estructuras reproductivas del hongo sean eliminadas, de esta forma al usar lixiviados posteriormente en cultivos no se generará un riesgo sanitario para los mismos.

De los cinco géneros de hongos identificados (Figura 2): Fusarium, Aspergillium, Mucor, Rhizopus, y Geomyces, cuatro son saprofitos y descomponedores de la materia orgánica, los factores relevantes de estos hongos es que se relacionan con los procesos de descomposición, en el caso del género Fusarium se puede presentar hasta temperaturas de hasta $37^{\circ} \mathrm{C}$, de acuerdo a esto, las temperaturas alcanzadas en un proceso de descomposición deben ser mayores a $40^{\circ} \mathrm{C}$ esto con 
el fin de eliminar estructuras reproductivas; como consecuencia de las elevadas temperaturas alcanzadas durante la fase termofílica, donde se destruyen las bacterias patógenas y parásitos presentes en los residuos de partida.

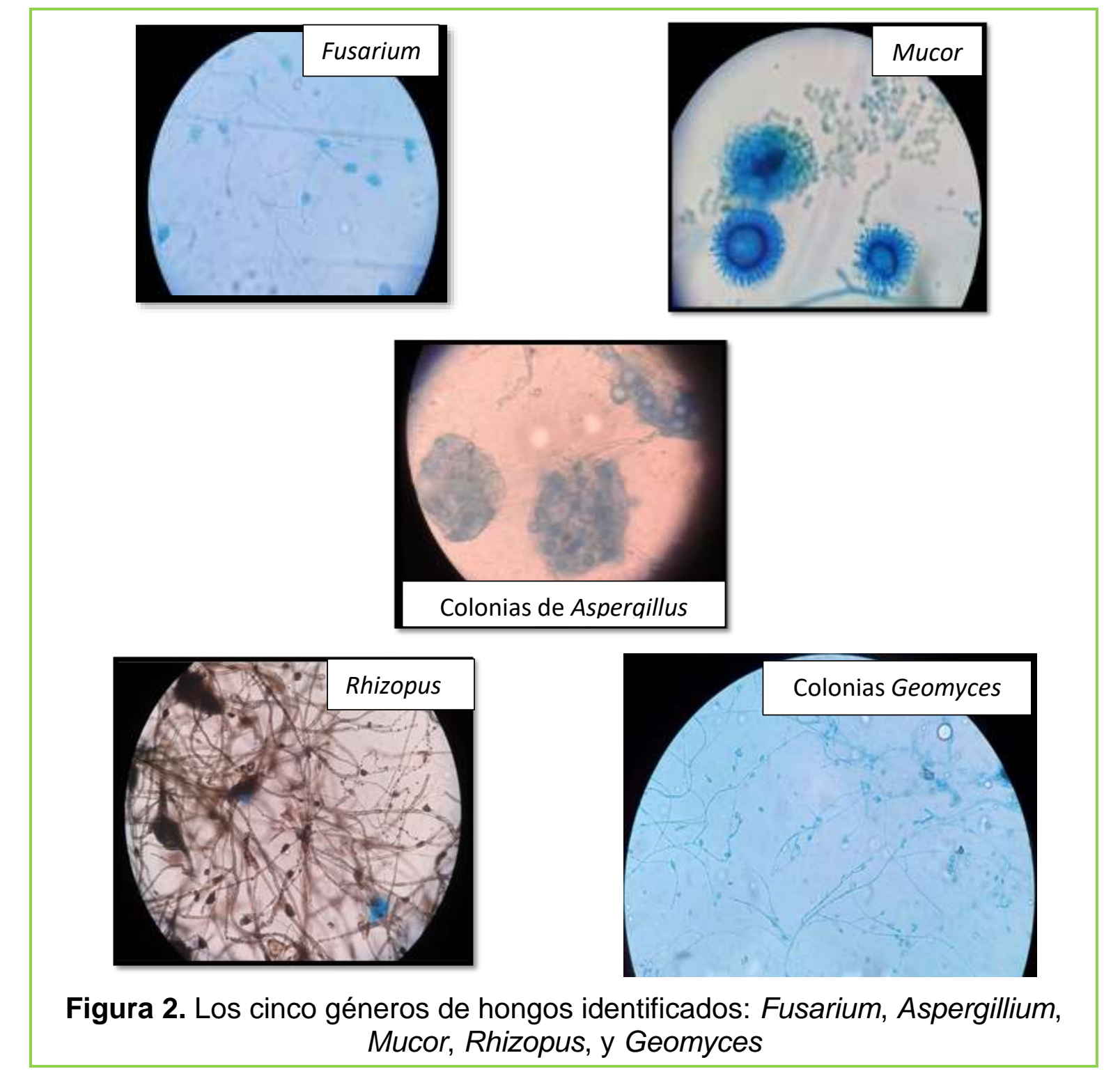

En dicha fase se da la higienización y en las subsiguientes podría ocurrir una recontaminación del material debido a varios factores: uso de utensilios contaminados con material fresco (pala para el volteo), o añadiéndolo después de la fase termófila, así mismo se puede contaminar en el almacenamiento y conservación del lixiviado, por otro lado el género Rhizopus es un importante descomponedor de las pectinas 
de la celulosa en los tejidos vegetales, lo que es conveniente debido a que los tejidos del raquis de plátano son bastante lignificados y tiene una baja relación carbono nitrógeno (C:N) de 70/1 para la cascara.

\section{Caracterización físico química de los lixiviados}

El pH y los sólidos totales (ST) de los lixiviados variaron entre 8.3 y $17.666 \mathrm{mg} / \mathrm{L}$ para los lixiviados de Fuente de Oro, y 8.9 y 18.882 mg/L para los de Villavicencio, presentando $\mathrm{pH}$ alcalino en todos los casos, y la característica de los ST es la materia suspendida o disuelta, sedimentable; se presentó una alta alcalinidad de los lixiviados que varió entre $13.529 \mathrm{mg}$ de $\mathrm{CaCO}_{3} / \mathrm{L}$ para los de Fuente de Oro y 14.100 mg de $\mathrm{CaCO}_{3} / \mathrm{L}$ para los de Granada; por otra parte la turbidez de las muestras varió entre 130 unidades nefelométricas de turbidez (NTU) en los lixiviados de Villavicencio y 231 NTU en los de Fuente de Oro; los contenidos de potasio $(\mathrm{K})$ de los lixiviados fueron altos variando entre 4.620 y 5.300 mg/L en Villavicencio y Granada respectivamente. Las muestras de Granada contienen K equivalente aproximadamente a 5.3 gramos/planta (Tabla 5). Al respecto Álvarez et al., (2013) afirman que la calidad de los lixiviados se ve influenciada por el manejo que se realice en el cultivo especialmente la fertilización y prácticas culturales, afectando la calidad del raquis, al igual que el protocolo de producción del lixiviado y el tiempo de curado.

El contenido de sodio ( $\mathrm{Na}$ ) varió de 10 a $34 \mathrm{mg} / \mathrm{L}$ en los lixiviados de las localidades de Granada y Villavicencio respectivamente, indicando bajos contenidos. El exceso de sodio puede provocar deficiencias de otros cationes, como potasio, calcio y magnesio; está directamente relacionado con la alcalinidad de los lixiviados (Espinosa y Molina, 1999). La dureza cálcica de los lixiviados fue considerada alta variando de 2.100 a $2.240 \mathrm{mg} / \mathrm{L}$ en la localidad de Villavicencio y Granada respectivamente. Altos contenidos de calcio, en la forma de pectatos de calcio, serían responsables de mantener unidas las paredes celulares de las plantas, originando mayor resistencia a la biodegradación de los materiales vegetales. Los altos niveles de calcio en los suelos pueden competir con la absorción de magnesio y potasio, causando la deficiencia de estos (Bohórquez, 2011). 
Tabla 5. Variables físico químicas analizadas en los lixiviados del plátano

\begin{tabular}{ccccc}
\hline Parámetro & Unidades & Media & Máximo & Mínimo \\
\hline $\mathrm{pH}$ & & 8.63 & $8.9(\mathrm{~L} 3)$ & $8.3(\mathrm{~L} 1)$ \\
Solidos totales & $\mathrm{mg} / \mathrm{L}$ & 18.379 & $18.882(\mathrm{~L} 3)$ & $17.666(\mathrm{~L} 1)$ \\
Alcalinidad & $\mathrm{mg} \mathrm{CaCO} / \mathrm{L}$ & 13.529 & $14.100(\mathrm{~L} 2)$ & $13.529(\mathrm{~L} 1)$ \\
Turbidez & $\mathrm{NTU}$ & 171 & $231(\mathrm{~L} 1)$ & $130(\mathrm{~L} 3)$ \\
Potasio & $\mathrm{mg} / \mathrm{L}$ & 4.890 & $5.300(\mathrm{~L} 2)$ & $4.620(\mathrm{~L} 3)$ \\
Sodio & $\mathrm{mg} / \mathrm{L}$ & 23.33 & $34(\mathrm{~L} 3)$ & $10(\mathrm{~L} 2)$ \\
Dureza cálcica & $\mathrm{mg} / \mathrm{L}$ & 2.164 .66 & $2.240(\mathrm{~L} 2)$ & $2.100(\mathrm{~L} 3)$ \\
Dureza total & $\mathrm{mg} / \mathrm{L}$ & 1.020 .53 & $1.120(\mathrm{~L} 3)$ & $861.6(\mathrm{~L} 1)$ \\
Hierro & $\mathrm{mg} / \mathrm{L}$ & 12.66 & $16(\mathrm{~L} 3)$ & $10(\mathrm{~L} 1)$ \\
Cloruros & $\mathrm{mg} / \mathrm{L}$ & 557 & $743(\mathrm{~L} 3)$ & $371(\mathrm{~L} 2)$ \\
DQO & & 2.462 .95 & $4.755(\mathrm{~L} 3)$ & $1.920(\mathrm{~L} 1)$ \\
DBO5 & & 1077 & $1.355(\mathrm{~L} 3)$ & $646(\mathrm{~L} 1)$ \\
DBO5/DQO & & 0.28 & $0.33(\mathrm{~L} 1)$ & $0.28(\mathrm{~L} 3)$ \\
\hline
\end{tabular}

$\mathrm{NTU}=$ Unidades nefelométricas de turbidez; $\mathrm{DQO}=$ Demanda química de oxígeno; $\mathrm{DBO}_{5}=$ Demanda biológica de oxígeno; Relación $\mathrm{DBO}_{5} / \mathrm{DQO}=0.78$. obtenida para el agua residual. $\mathrm{L} 1=$ Fuente de Oro; L2 = Granada; L3 = Villavicencio.

La dureza total de los lixiviados también fue alta variando de 861.6 a $1.120 \mathrm{mg} / \mathrm{L}$, en los lixiviados de Fuente de Oro y Villavicencio respectivamente, indicando posiblemente una menor biodegradibilidad en los últimos. Los contenidos de hierro $(\mathrm{Fe})$ en los lixiviados variaron entre 10 y $16 \mathrm{mg} / \mathrm{L}$ en las localidades de Villavicencio y Fuente de Oro, siendo bajos. Se encontraron altos contenidos de cloruros en los lixiviados variando entre 371 y $743 \mathrm{mg} / \mathrm{L}$ para Granada y Villavicencio (Tabla 5). La DQO y la $\mathrm{DBO}_{5}$ de los lixiviados fueron menores en la localidad de Fuente de Oro y mayores en Villavicencio; la biodegradabilidad ( $\left.\mathrm{DBO}_{5} / \mathrm{DQO}\right)$ de los materiales fue inversa, con valores que variaron de 1.920 a 4.755 ; 646 a 1.355 ppm respectivamente y de 28 a $33 \%$ inversamente. Posiblemente la baja biodegradabilidad de los materiales puede ser debida a que es lixiviado joven. 
Parámetros como la conductividad, la alcalinidad y la dureza, tienen una relación directamente proporcional, ya que dependen de la presencia de iones en los lixiviados (Kang et al., 2002).

Relacionando tanto los aspectos microbiológicos y fisicoquímicos con la biodegradabilidad de los lixiviados de las tres localidades se nota una interacción entre el tiempo de maduración del lixiviado y los contenidos fisicoquímicos que en consecuencia definirán el tipo de poblaciones microbiológicas presentes en el lixiviado, y seguidamente estos influyen en la demanda biológica de oxígeno; las bacterias, los actinomicetos y los hongos consumen los residuos directamente y se conocen como compostadores de primer nivel, los actinomicetos asumen la dirección durante las etapas finales de descomposición, los actinomicetos dan el olor característico a tierra ya que son especialmente importantes en la formación del humus, sus enzimas le permiten romper químicamente residuos ricos en celulosa lignina quitina y proteínas (Pereira et al., 2007).

La presencia de esporas o estructuras reproductivas de estos hongos y bacterias en el lixiviado no significa que el proceso de higienización en los compostajes no sea efectivo, debido a que al ser un medio nutritivo alto en potasio (4.620-4.750 $\mathrm{mg} / \mathrm{L}$ ), y sodio (26.2-34.0 mg/L) se convierte en un medio básico, que para el caso de las tres localidades el pH osciló entre 8.3 y 8.9 lo cual es favorable, puesto que bacterias como las del filo actinomicetos aceleran sus procesos de descomposición en pH altos; sin embargo para el caso de hongos como Rhizopus el pH alcalino no es favorable, un estudio realizado por Pereira et al., (2007) determinó que los máximos valores tanto en velocidad de crecimiento como en área de hongos micorrizógenos se daba en el pH 5.8 a 6.8, lo cual puede ser una respuesta a la baja población de hongos presentes en los lixiviados debido a que el pH influye en que haya menos unidades formadoras de colonia (Castrillón et al., 2006).

De acuerdo a todas las interrelaciones que existen entre los diferentes factores, se deduce que un solo análisis representa las características fisicoquímicas del lixiviado a la edad de 4 meses, las cuales a nivel microbiológico no son favorables para la aplicación a cultivos, sin embargo los niveles altos de potasio son un aporte 
importante de este nutriente al suelo, que para el cultivo de plátano después del $\mathrm{N}$, $\mathrm{Ca}, \mathrm{Mg}$ y $\mathrm{P}$, presenta uno de los mayores niveles de extracción, por lo tanto en esta etapa sería un fertilizante excelente.

El pH básico en todos los lixiviados a diferencia de lo reportado en la literatura no estuvo asociado con los contenidos de bases $\mathrm{Ca}, \mathrm{K}$ y $\mathrm{Na}$, puesto que estos elementos le dan la característica de basicidad y el $\mathrm{pH}$ alcalino al lixiviado, posiblemente asociado al efecto de los cloruros presentes en este. La correlación de Pearson en ST con la alcalinidad fue altamente positiva $(r=0.97)$, igualmente para los contenidos de $\mathrm{Fe}(\mathrm{r}=0.89)$ y la DQO $(r=1.00)$; esta variable fue negativamente asociada con la turbidez $(r=-1.0)$ y la dureza total $(r=-0.97)$. Al respecto, la determinación de los ST es una prueba indispensable que junto con otros parámetros proporciona información de la eficiencia de remoción del proceso, e indirectamente, de la concentración de biomasa en los lixiviados (Morillo y Fajardo, 2005).

La alcalinidad fue altamente relacionada con la DQO $(r=0.95)$, pero no con la turbidez y la dureza total ( $r=-0.98$ y $r=-0.97$ respectivamente), resultado no coincidente con el afirmado por Kang et al., (2002) quienes mencionan que parámetros como la conductividad, la alcalinidad y la dureza, tienen una relación directamente proporcional, ya que dependen de la presencia de iones en los lixiviados; esta diferencia posiblemente pudo deberse a la turbidez de los lixiviados.

La alcalinidad cuantifica la capacidad del agua residual de neutralizar ácidos, y se mide en $\mathrm{mg}$ de $\mathrm{CaCO}_{3} / \mathrm{L}$; es debida principalmente a la presencia de iones bicarbonato, carbonato e hidroxilo, y en este caso se le puede atribuir al alto contenido de calcio y al $\mathrm{pH}$, y aunque la alcalinidad está relacionada con las bases potasio y sodio, en este caso mostró más afinidad con el Fe; es posible que la presencia de cloruros haya disminuido el efecto positivo de estos dos nutrientes. Los cloruros, más que por su carencia, que es muy poco común, son importantes por exceso, el cual puede producir quemaduras en las hojas comenzando por su ápice, pudiendo llegar a caerse (Solís, 2007). 
Los contenidos de $\mathrm{K}$ y $\mathrm{Na}$ en los lixiviados estuvieron altamente relacionados con el $\mathrm{pH}$, alcalinidad, turbidez y ST ( $r=0.99$ y $0.91 ; r=0.78$ y $0.88 ; r=0.91$ y $0.99 ;$ y $r=0.93$ y 0.97 respectivamente), más sin embargo la variable $\mathrm{K}$ no guardó correlación con $\mathrm{Na}$, ni con $\mathrm{Cl}$, ni con $\mathrm{DBO}_{5}(\mathrm{r}=-0.99,-0.94$ y -0.98$)$. En tanto, que el $\mathrm{Na}$ fue negativamente asociado con la dureza clásica $(r=-1.0)$.

Los lixiviados son una buena fuente de nutrientes, sobre todo en el aporte de elementos como potasio y calcio; sin embargo, la aplicación de estos directamente a las plantas puede ocasionar afectaciones a las mismas principalmente sí son jóvenes, el exceso de potasio puede provocar una carencia de nitrógeno, de calcio o de magnesio; la carencia de estos elementos ocasiona lento crecimiento en las plantas, dificultan la fotosíntesis y ocasionan amarillamiento en las partes aéreas. Excesos de potasio pueden quemar las semillas o plantas pequeñas puesto que es un elemento muy turgente y las células sufren plasmólisis, reventándose porque no soportan la presión osmótica y tienden a secarse (Torrez et al., 2018).

Sin embargo, una de las posibles causas por las cuales el lixiviado puede llegar a ser un agente de control fúngico son los altos contenidos de potasio presentes en los lixiviados; de acuerdo con González, (2015) este nutriente interviene positivamente en el metabolismo del vegetal favoreciendo la síntesis de sustancias anti fúngicas y un mayor crecimiento del vegetal; también incide positivamente en el engrosamiento de cutícula y epidermis que dificultan físicamente la penetración de los patógenos y los vectores. Por otro lado, el potasio interviene directamente en la regulación estomática, siendo vital en la regulación osmótica mejorando sustancialmente el funcionamiento vegetal bajo condiciones de estrés ambiental. Sumado a esto último, y en un mismo sentido de acción, el potasio interviene en la formación de raíces, con lo cual el cultivo mejora su capacidad de exploración del suelo en busca de otros nutrientes y de agua, en general está asociado con la activación de los sistemas de defensa natural de las plantas contra las enfermedades fungosas. A su vez la dureza clásica tampoco se correlacionó con los contenidos de $\mathrm{Cl}(\mathrm{r}=-0.99)$ ni con los de la $\mathrm{DBO}_{5}(\mathrm{r}=-0.92)$. La dureza total tuvo 
una correlación negativa con la DQO ( $\mathrm{r}=-0.95)$, el Fe correlaciono positivamente con $\mathrm{DQO}(\mathrm{r}=0.92)$, y la $\mathrm{DBO}_{5}$ correlacionó positivamente con la $\mathrm{DQO}(\mathrm{r}=0.86)$.

\section{Biodegradabilidad de los lixiviados}

La DQO se correlacionó positivamente con $\mathrm{K}, \mathrm{Na}$, dureza clásica y $\mathrm{CL}$, en tanto que la $\mathrm{DBO}_{5}$ guardó una estrecha relación con $\mathrm{pH}$, solidos totales, turbidez, Fe y la DQO; sin embargo, los resultados de la comparación de Tukey, no mostró diferencias $(P>0.05)$ entre las localidades de Villavicencio y Granada tanto para la DQO como

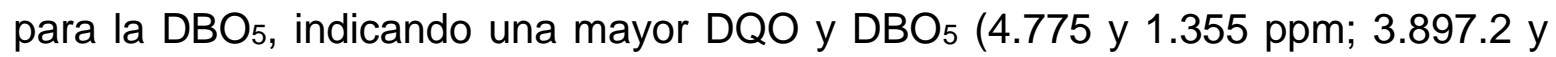
1.230 ppm respectivamente); pero si se encontraron diferencias $(\mathrm{P}<0.05)$ con los de Fuente de Oro, siendo que la DQO y la $\mathrm{DBO}_{5}$, fue menor (1.920 y $646 \mathrm{ppm}$ respectivamente), probablemente debido a una menor actividad microbiana. Sin embargo, al analizar la relación $\mathrm{DQO} / \mathrm{DBO}_{5}$, los resultados de biodegradabilidad de los lixiviados no presentaron diferencias significativas $(P>0.05)$, por lo cual se clasificaron entre poco biodegradables y no biodegradables (Tabla 6).

Tabla 6. Relación $\mathrm{DQO} / \mathrm{DBO}_{5}$ (Biodegradabilidad de los lixiviados del raquis de plátano)

\begin{tabular}{|c|c|c|c|c|}
\hline \multicolumn{4}{|c|}{ Análisis fisicoquímico de agua residual } & \multirow{2}{*}{$\begin{array}{c}\mathrm{DBO}_{5} / \mathrm{DQO} \\
\text { degradabilidad (\%) }\end{array}$} \\
\hline Localidad & Parámetro & Método & $\begin{array}{l}\text { Resultado } \\
\text { (ppm) }\end{array}$ & \\
\hline \multirow{2}{*}{ Fuente de Oro } & DQO & ASTM 5220 D & $1.920 .0^{\mathrm{b}}$ & \multirow{2}{*}{$30^{a}$} \\
\hline & $\mathrm{DBO}_{5}$ & ASTM 5210 B & $646^{\mathrm{b}}$ & \\
\hline \multirow{2}{*}{ Granada } & DQO & ASTM 5220 D & $3.897 .2^{\mathrm{a}}$ & \multirow{2}{*}{$30^{\mathrm{a}}$} \\
\hline & $\mathrm{DBO}_{5}$ & ASTM $5210 \mathrm{~B}$ & $1230^{\mathrm{a}}$ & \\
\hline \multirow{2}{*}{ Villavicencio } & DQO & ASTM 5220 D & $4.775 .0^{\mathrm{a}}$ & \multirow{2}{*}{$20^{\mathrm{a}}$} \\
\hline & $\mathrm{DBO}_{5}$ & ASTM 5210 B & $1.355^{\mathrm{a}}$ & \\
\hline
\end{tabular}

$\mathrm{DQO}=$ Demanda química de oxígeno, $\mathrm{DBO}_{5}=$ Demanda bioquímica de oxígeno.

Letras distintas indican diferencias estadísticas $(P<0.05)$. 


\section{CONCLUSIONES}

Se identificó un orden de bacterias Actinomicetos, y cuatro géneros Clavibacter, Erwinia, Pseudomonas y Agrobacterium y cinco géneros de hongos Fusarium, Aspergillium, Mucor, Rhizopus y Geomyces, distribuidos en las tres localidades con frecuencia variable.

La identificación microbiológica de las muestras permitió profundizar en las características que presentan los lixiviados y mostrar la importancia del tiempo de maduración del mismo para poder eliminar cualquier tipo de microorganismo que pueda perjudicar las plantas en las que se use; en este mismo sentido, el principal agente de riesgo fitosanitario es Fusarium el cual es causante de enfermedades limitantes en varios cultivos, por lo tanto es recomendable establecer el tiempo de estabilización del lixiviado que permita eliminar cualquier riesgo de problemas fitosanitarios.

Se recomienda dejar madurar el lixiviado por lo menos un año para que durante el proceso de descomposición se disponga del tiempo suficiente para que se pueda eliminar cualquier microorganismo patógeno para los cultivos, sin embargo, es necesario profundizar y evaluar el contenido microbiológico del lixiviado a esta edad, sí se desea garantizar un uso confiable al agricultor; de hecho, se recomienda realizar mínimo tres evaluaciones al lixiviado en el transcurso de un tiempo no menor a un año, con lo cual se pueda establecer una curva de biodegradabilidad de los lixiviados provenientes del material vegetal.

Los lixiviados de Fuente de Oro y Granada mostraron mayor biodegradabilidad en comparación con los de Villavicencio.

\section{REFERENCIAS BIBLIOGRÁFICAS}

1. Agrios, G. Fitopatología, 2a Ed. México: Limuda, 952 p. 2005.

2. Álvarez, E., Pantoja, A., Ceballos, G., Gañan, L. Producción de lixiviado de raquis de plátano en el Eje Cafetero de Colombia, Centro Internacional de Agricultura Tropical (CIAT) 6 p. 2013. Disponible En: http://www.fao.org/3/aas091s.pdf 
3. Ardila, A., Arriola, E., Reyes, J., Berrio, E., Fuentes, G. Mineralización de etilenglicol por foto-fenton asistido con ferrioxalato. Revista Internacional de Contaminación Ambiental, 32 (2): 213-226. 2016.

4. Aristizábal, M., Jaramillo, C. Identificación y descripción de las etapas de crecimiento del plátano Dominico Hartón (Musa AAB). Revista Agronomía, 18 (1): 29-40. 2010.

5. Benavides, K. Caracterización microbiológica de lixiviados de materias primas para la fabricación de un compostaje de material ruminal. Tesis de Grado Especialista en Microbiología Industrial, Facultad de Ciencias de la Salud Manizales Caldas, Universidad Católica de Manizales, 132 p. 2010. Disponible En:

http://repositorio.ucm.edu.co:8080/jspui/bitstream/handle/10839/74/Karen\%20 Adriana\%20Benavides. pdf? sequence $=1$ \&isAllowed $=y$

6. Bohórquez, W. Papel de la interacción de calcio y boro en el ennegrecimiento de los pétalos en rosa (Rosa sp.). Tesis de grado Magister en Ciencias Agrarias - Fisiología de cultivos, Facultad de Agronomía, Universidad Nacional de Colombia, Bogotá, Colombia. 117 p. 2011. Disponible En: http://bdigital.unal.edu.co/4370/1/790634.2011.pdf

7. Castaño, A., Aristizábal, M., González H. Requerimientos hídricos del plátano dominico-hartón (Musa aab simmonds) en la región santágueda (Palestina, Caldas). Revista U.D.C.A Actualidad \& Divulgación Científica, 15 (2): 331-338. 2012.

8. Cruz, I., Márquez, I., García, R., Carrillo, J., León, J., Allende, R. Identificación de hongos mucorales causantes de la pudrición blanda en frutos de papaya (Carica papaya L.) en México. Revista Mexicana de Fitopatología, 35 (3): 397417. 2017.

9. Espinosa, J., Molina, E. Acidez y encalado de los suelos. $1^{\text {a }}$ Ed, Ecuador: International Plant Nutrition Institute 46 p. 1999. Disponible En: http://www.cia.ucr.ac.cr/pdf/libros/Acidez $\% 20$ y 20 encalado\%20de\%20suelos, \%20libro\%20por\%20\%20J\%20Espinosa\%20y\%20E\%20Molina.pdf.

10. Figueroa, M., Rodríguez, R., Guerrero, B., González, M., Pons, J., Jiménez, J., Ramírez, J., Andrio, E., Mendoza, M. Caracterización de especies de Fusarium asociadas a la pudrición de raíz de maíz en Guanajuato, México. Revista Mexicana de Fitopatología, 28 (2): 124-134. 2010.

11. González, Y. Los actinomicetos: una visión como promotores de crecimiento vegetal. Tesis de Grado Microbióloga Agrícola y Veterinaria, Facultad de Ciencias, Pontificia Universidad Javeriana, Bogotá, Colombia. 37 p. 2010. Disponible https://repository.javeriana.edu.co/bitstream/handle/10554/8665/tesis618.pdf;s equence $=1$

12. González, F. Evaluación agronómica del híbrido de pimiento quetzal (Capsicum annum L.) con aplicaciones de cinco niveles de fosfito de potasio. Tesis de grado Ingeniero Agrónomo. Facultad de Ciencias Agrarias, Universidad de Guayaquil. Guayaquil, Ecuador. 97 p. 2015. Disponible En: http://repositorio.ug.edu.ec/bitstream/redug/7351/1/TESIS\%20FREDDI\%20GO NZALEZ.pdf 
13. Hernández, A., Bautista, S., Velázquez, M., Trejo, J. Identification of Rhizobium stolonifer Ehrenb. (Ex Fr.) Lind, causal agent of Rhizopus rot disease of fruits and vegetables. Revista Mexicana de Fitopatología, 24: 65-69. 2006.

14. Kang, K., Shin, H., Park, H. Characterization of humic substances present in landfill leachates with different landfill ages and its implications. Water Research, 36 (16): 4023-4032. 2002.

15. Losada, J. Caracterización de los lixiviados generados en el proceso de compostaje provenientes de residuos orgánicos de plaza de mercado y su uso como complemento nutricional para cultivos hidropónicos. Tesis de grado Ingeniero ambiental y sanitario. Universidad de la Salle. Bogotá, Colombia. 170 p. $2012 . \quad$ Disponible En: http://repository.lasalle.edu.co/bitstream/handle/10185/14023/T41.09\%20L896 c.pdf? sequence $=2 \&$ isAllowed $=y$

16. Mazzeo, M., León, L., Mejía, L., Guerrero, L., Botero, J. Aprovechamiento industrial de residuos de cosecha y poscosecha del plátano en el Departamento de Caldas. Revista Educación en Ingeniería, 5 (9): 128-139. 2010.

17. Mendoza, P., López, V. Estudio de la calidad del lixiviado del relleno sanitario la esmeralda y su respuesta bajo tratamiento en filtro anaerobio piloto de flujo ascendente. Tesis de grado Ingeniero Químico. Facultad de Ingeniería y Arquitectura, Universidad Nacional de Colombia. Manizales, Colombia. 125 p. 2004.

Disponible http://bdigital.unal.edu.co/1059/1/patriciamendozasalgado.2004 .pdf

18. Morillo, F., Fajardo, E. Estudio de los reactores UASB para el tratamiento de lixiviados del relleno sanitario la Esmeralda. Tesis de Especialista en Ingeniería Ambiental - Área Sanitaria. Facultad de Ingeniería y Arquitectura, Universidad nacional de Colombia. 84 p. 2005. Disponible En: http://bdigital.unal.edu.co/1980/1/fernandacristinamorilloleon.2005.pdf

19. Obregón, M., Rodríguez, P., Morales, J., Salazar, M. Hospedantes de Ralstonia solanacearum en plantaciones de banano y plátano en Colombia. Revista Facultad Nacional de Agronomía Medellín, 61 (2): 4518-4526. 2008.

20. Parada, R., Marguet, E., Vallejo, M. Aislamiento y caracterización parcial de actinomicetos de suelos con actividad antimicrobiana contra bacterias multidrogo-resistentes. Revista Colombiana de Biotecnología, XIX (2): 15-23. 2017.

21.Pereira, G., Herrera, J., Machuca, A., Sánchez, M. Efecto del pH sobre el crecimiento in vitro de hongos ectomicorrícicos recolectados de plantaciones de Pinus radiata. Revista Bosque (Valdivia), 28 (3): 215-219. 2007.

22. Reyes, J., Henao, A., Ardila, A. Degradación fotocatalítica de los colorantes rojo reactivo 120 y azul reactivo 4 hidrolizados usando $\mathrm{TiO}_{2}$ dopado con hierro 0 nitrógeno. Revista Politécnica, 11 (20): 9-19. 2015.

23. Salazar, L., Antolinez, I. Tratamiento de lixiviados, casos prácticos en diferentes temperaturas. En: II Simposio Iberoamericano de Ingeniería de Residuos, Barranquilla, 24 y 25 de septiembre de 2009, 15 p. 2009. Disponible En: http://www.redisa.net/doc/artSim2009/TratamientoYValorizacion/Tratamiento\% 20de\%20lixiviados casos\%20pr\%C3\%A1cticos\%20en\%20diferentes\%20temp eraturas.pdf. 
24. Silva, M., Andrade, E., Salamanca, V. Guías de laboratorio de Microbiología agrícola. Universidad de los Llanos. SP. Guía de consulta en el laboratorio. 1999.

25. Solís, A. El cultivo de Plátano (genero musa) en México. Trabajo de grado Ingeniero Agrónomo en Horticultura. Departamento de Horticultura, Universidad Autónoma Agraria "Antonio Narro". 81 p. 2007. Disponible En: http://repositorio.uaaan.mx:8080/xmlui/bitstream/handle/123456789/4956/T164 94\%20\%20\%20SOLIS\%20ROSALES,\%20\%20ADALBERTO\%20\%20\%20TE SIS.pdf?sequence $=1$

26. Torrez V, Agudelo A, García L, Padilla L. Caracterización de lixiviados como alternativa que contribuya a la mitigación de contaminantes. Revista lon, 31 (1): 59-63. 2018.

27. Universidad Nacional de Córdoba (UNC). Guía de actividades prácticas microbiología agrícola. Facultad de Ciencias Agropecuarias, 88 p. 2015. Disponible En: http://agro.unc.edu.ar/ microbiologia/wpcontent/uploads/2014/04/Guia-de-Trabajos-Practicos.pdf.

28. Atlas, R., Bartha, L. Ecología microbiana y microbiología ambiental. 4⿳a Ed. Pearson-Addison Wesley. Madrid, España. 677 p. 2005.

29. Urbina, C. Enfermedades causadas por bacterias. En: Fitopatología general. Universidad Católica Agropecuaria del Trópico Seco. Estelí, Nicaragua 19 p. 2011. Disponible https://martinurbinac.files.wordpress.com/2011/08/unidadad-vii-enfermedadescausadas-por-bacterias-final.pdf.

30. Urbina, C. Enfermedades causadas por hongos. En: Fitopatología general, Universidad agropecuaria del trópico seco, Estelí, Nicaragua. 16 p. 2011. Disponible https://virtual.uptc.edu.co/ova/fito/archivo/GENERALIDADES.pdf

31. Velázquez, M., Bautista, S., Hernández, A., Guerra, M., Amora, E. Estrategias de control de Rhizopus stolonifer Ehrenb (Ex Fr.) Lind, agente causal de pudriciones postcosecha en productos agrícolas. Revista Mexicana de Fitopatología, 26 (1): 49-55. 2008. Disponible En: http://www.redalyc.org/pdf/612/61226108.pdf

32. Ventura, M. Identificación de bacterias fitopatógenas en cultivos de papaya (Carica papaya) en las fincas el Pantanal y el Subín, ubicadas en el departamento del Petén, Guatemala. Tesis de grado Química Bióloga Facultad de Ciencias Químicas y Farmacia, Universidad de San Carlos de Guatemala. 54 p. 2007. Disponible En: http://biblioteca.usac.edu.gt/tesis/06/06 2520.pdf. 